\title{
The Self-Survey in the Elementary School an Experiment in Cooperation
}

\section{R. H. Lane}

To cite this article: R. H. Lane (1920) The Self-Survey in the Elementary School an Experiment in Cooperation, The Journal of Educational Research, 1:3, 172-176, DOI: 10.1080/00220671.1920.10879039

To link to this article: http://dx.doi.org/10.1080/00220671.1920.10879039

Published online: 15 Dec 2014.

Submit your article to this journal \lceil

Q View related articles $\longleftarrow$ 


\title{
THE SELF-SURVEY IN THE ELEMENTARY SCHOOL: AN EXPERIMENT IN COOPERATION
}

\author{
R. H. LANE \\ Assistant Superintendent of Schools, Los Angeles, California
}

The following notice appeared in the Los Angeles, California School Journal for January 20, 1919:

The Division of Educational Research has in mind for the near future the development of a plan for the Self-Survey of the Elementary School by the Principal and his Associate teachers. This will be accomplished partly by means of standard and other tests, partly by an investigation along uniform lines into several phases of the administration and organization of the school. It is a matter of great gratification to the members of this Division that the courses along this line at the State Normal School, have been so well attended, showing that the time is ripe for an enterprise of this kind.

It must be obvious that such a scheme can be successfully worked out only through the cooperation of those principals who wish to undertake the work. All principals who are interested are asked to communicate at once with the Director, stating that they will be willing to take the time during the spring term to give certain tests and undertake certain studies into the organization and administration of their schools. This will necessitate a few meetings in the near future, but every effort will be made to avoid taking an undue amount of the principals' time. It is suggested that not more than twenty principals form the first group to undertake this work.

In spite of the restriction placed upon the number of members, the class which began work in February was made up of twentyeight elementary school principals, representing all types of schools from the large well-graded city school in the metropolitan district to the small ungraded rural school. As a check upon the accuracy of the methods employed by members of the class, the director carried on the work outlined for members of the class simultaneously in five other elementary schools, whose principals and teachers contributed largely to the success of this enterprise by their hearty cooperation.

The members of the class were given, in addition to the preliminary instructions for giving the first tests, some general advice as to the spirit in which the enterprise was to be carried out, in something like the following vein: 
Before embarking on this enterprise the principal should endeavor to secure to the fullest possible degree the interest and cooperation of his teachers. The tests should not be suddenly sprung upon the teachers without warning, but every effort should be made to prepare carefully and gradually the plans for the campaign. It is inevitable that teachers unfamiliar with educational measurement should look upon a series of tests as an attempt to uncover the weak spots in their teaching and the principal must see to it that his teachers cultivate that fine impersonal attitude which weicomes measurement as a possible solution of certain vexed classroom problems. He should emphasize the fact that one of the greatest contributions of educational psychology is its insistence on the complexity of the learning process, that a child's success or failure in his school work is the product of many factors of which the quality of teaching is only one factor, and that a teacher must not charge herself with the failure of a pupil until she has eliminated all other possible factors from the situation. The reputation of a successful teacher should be such an assured fact both in her own mind and that of her fellow teachers, that the failure of a class in any test or series of tests should not even suggest that the teacher is personally to blame for the result. The finest quality which a teacher can possess is that scientific habit of mind which welcomes occasional class or individual failure as a challenge to her powers of analysis, and interpretation.

Some very definite directions were given as to the preliminary reading each member of the class was to do. Reference was made to the standard books on educational measurement by Thorndike, Monroe, Rugg, and Alexander; to the monographs of the University of Chicago, and to such bulletins as those prepared by the University of Illinois, the city of Boston, the Kansas State Normal School, and Teachers' College, Columbia University.

After the first test had been given by members of the class in their respective schools, the class was called together again for discussion upon the problems which arose in the conduct of the work. One of the chief problems was for the novice to learn the technic of educational statistics. In many cases individual help as well as class help became necessary. Reference was made to the excellent chapters in Rugg's Statistical Methods Applied to Education. ${ }^{1}$ Finally it became necessary to send out some brief lessons in mimeographed form upon the meaning and method of finding the median, mean, mode, etc.

Seven distinct tests in arithmetic, three tests in reading, the Trabue scale in language, and selections from the Hahn-Lackey scale in geography comprised the material used during the term.

${ }^{1}$ Rugg, H. O. Statistical methods applied to education. Boston: Houghton Mifflin Co., 1917. 
An effort was made to keep constantly before the class the need for intelligent interpretation of the results in each test. It may be safely laid down as a general rule that any test which does not lead to definite improvement in the progress of pupils is a test which is not worth giving. It is true that having found the "average" or central tendency of a class in some performance the principal is possessed of information which justifies him in saying that a particular class in a particular performance reached, exceeded, or fell below the accepted standard in such case made and provided, but the classroom teacher will not derive much help thereby. In any test four steps should be recognized: (1) The test gives us the facts in the case; (2) It shows which pupils are failing in that phase of instruction covered by the test. Hence if the test is to function: (3) The reason for those individual failures must be found; (4) Remedial measures must be taken to correct those failures.

For a full treatment of this subject of interpretation see Dr. Monroe's Measuring the Results of Teaching. ${ }^{2}$ In addition, the results from experiments in the control schools along this line will be found illuminating.

One of the fifth-grade classes tested early in March, attained a median in the Quick Test in Arithmetic ${ }^{3}$ of 2.5 problems correct in six minutes, an obviously unsatisfactory result. The common prescription of the classroom teacher in such cases is "more drill," but it was pointed out that more drill would be ineffective unless the cause for each individual failure was located. This was done and the following instances of failure noted.

1. In addition several children knew single combinations perfectly, i.e., 6 plus 7 , but failed on similar combinations when extended into decades, i.e., 36 plus 7, 47 plus 6 , etc.

2. In addition of four columns children had not been taught to place the "carrying figure" above or below successive columns, hence if their attention wavered slightly, the carrying figure was forgotten and the addition had to be gone over from the beginning.

3. In long division many children did not know how to find the first figure of the quotient.

${ }^{2}$ Monroe, Walter S. Measuring the results of teaching. Boston: Houghton Mifflin Co., 1918.

${ }^{3}$ Second year book of the Division of Educational Research, Los Angeles, California, 1919 (Los Angeles City School District No. 21) p. 3. 
4. In the following problem a girl worked as follows:

$$
\text { 36) } \begin{gathered}
\frac{4}{16236} \\
144
\end{gathered}
$$

She then asked the observer if one added or subtracted 144 to or from 162 !

By means of diagnosis of this kind and very intelligent "follow up" work by the teacher, the class in June attained a median of 5.2 problems correct, an improvement of over 100 percent.

In another control school several children were located who were very poor in oral reading with respect both to speed and accuracy. Careful records were made of these children by means of Gray's Oral Reading Test (Standardized Paragraphs) and individual attention was paid to each child by his teacher with a view to eliminating sources of difficulty. At that time, the writer made the following recommendations to the teachers.

\section{TO THE TEACHER}

I present herewith an accurate record of the scores of those children who had unusual difficulty in their oral reading tests. Let us repeat the test in June to note improvement. Failure in oral reading is due to one or all of the following causes: (a) Deficient vocabulary, i.e., lack of a sufficiently large number of words which the pupil is able to recognize at sight; (b) lack of phonic power to analyze unfamiliar words; (c) lack of ability to move the eye along swiftly enough to catch the text in large units or phrases-"eye sweep"; (d) faulty or slovenly enunciation; (e) unfamiliarity in the middle grades with the derivation of words, i.e., word analysis; (f) lack of adequate material for rapid oral reading, i.e., easy supplementary readers.

I therefore recommend exercises as follows:

(a) Vocabulary drills to enlarge the vocabulary of sight words.

(b) Phonic drills to give power over unfamiliar words (see Gordon and Beacon Manuals).

(c) Word analysis drills (see Horace Mann Readers).

(d) Frequent time exercises in oral reading to cultivate rapidity.

(e) Enunciation drills.

A repetition of the test in June showed marked improvement.

A word of caution must be given to the principal who gives a test and finds the result below standard. The obvious explanation is that the teacher of the class is a poor teacher, but one soon learns to distrust this easy and obvious explanation. In one of the control schools several primary classes failed in a simple reading test. The personnel of the teaching force was of so high a 
character that the factor of poor teaching was quickly eliminated from the situation. After a careful investigation by the principal the following reasons for the failure were found:

1. The pupils in the failing classes had been victims of half-day sessions for several terms.

2. The pupils had had a succession of teachers in the preceding terms, one class alone having had seven different teachers in the ten months of school.

3. There had been several classes in each room at a time, i.e., B2, A2, B3, A3, with the result that in the effort to care for all four classes the amount of time available to the teacher for individual instruction was practically nil.

4. The teachers had not had clearly in mind what constitutes desirable standards of promotion from one class to another, with the result that the classes were poorly graded.

5. Each class had a relatively large number of mentally defective children who were incapable of profiting by classroom instruction in large groups.

At the opening of the fall term 1919, principals were invited to join new Self-Survey Classes along the lines described above. Twenty-two of the original twenty-eight principals registered for membership in an advanced class, while fifty-four other principals registered for elementary classes, necessitating the formation of four sections in the Self-Survey Class, three for beginners and one for advanced students. The work of the beginners for 1919-1920 will be to cover the better known educational tests, while the advanced pupils will study especially group intelligence tests.

Considerable attention has already been given to the Group Point Scale of Intelligence "Schedule D" devised by Dr. and Mrs. Pressey of Indiana University. ${ }^{4}$ This is being given to a large number of A6 classes with some very interesting results. Later on, it is planned to experiment with the Otis Group Tests in eighth-grade classes. The advanced section of the Self-Survey Class will experiment also with Dr. Strayer's Score Card for City School Buildings. Los Angeles has many types of school buildings, and it is believed that an intensive study of the construction of these will result in an awakened interest in better buildings.

" Pressey, S. L. and L. W. "A group point scale of intelligence," Journal of Applied Psychology, 2:250-69, September, 1918. The test may be purchased from ndiana University, Bloomington, Indiana. 